\title{
Correspondence
}

\section{Revived species: how would they survive?}

Viewing the revival of extinct species as a laboratory exercise overlooks key behavioural and ecological factors that cannot easily be reproduced (S. Kumar Nature 492, 9; 2012). Hence a recreated dodo might look and feel like one - but it wouldn't quite be a dodo.

Also, re-establishing an extinct species would mean following procedures that are normally used to introduce captive-bred animals to the wild. However, these repopulation attempts have contributed only marginally to biodiversity conservation, largely because the animals do not know how to interact with other members of their species or with their new environment.

Extant species can be trained on the basis of what we have learned from wild individuals, but such information is sparse or non-existent for extinct species. In the absence of their proper ecological niche, 'revived' species reintroduced into the wild would be unlikely to survive.

Diogo Veríssimo Durrell Institute of Conservation and Ecology, University of Kent, UK. dv38@kent.ac.uk

Laure Cugnière Zoological Society of London, UK.

\section{Revived species: where will they live?}

Subrat Kumar suggests that we should preserve the DNA of vanishing organisms such as tigers so that they can be regenerated later (Nature 492, 9; 2012). But extinctions do not just represent the loss of species - they are the pervasive disintegration and destabilization of ecological networks.

Species are more than the sum of their genes: they are the manifestation of reciprocal interconnectivities between organisms and their environment (C. S. Elton Animal Ecology Univ. Chicago Press, 2001). Modern

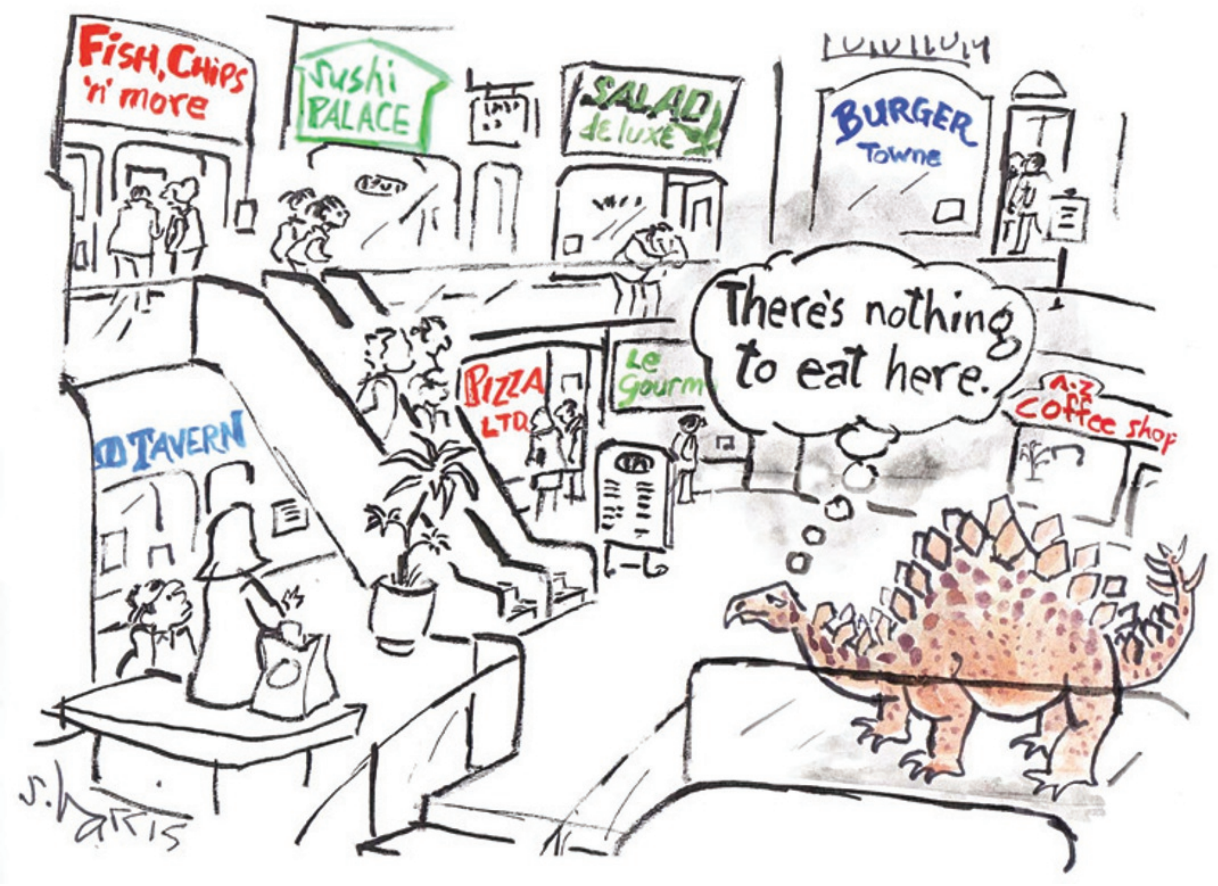

extinctions are an irrefutable symptom of habitat loss and the unravelling of biological processes. If we cannot preserve India's forests and mangrove swamps, for instance, then we cannot save its tigers.

Biotechnology has a role in conservation, but it is not the solution to extinction. Instead, we must protect the integrity of ecosystems and their inherent dynamics. Freezing the tiger's DNA amounts to little more than handing on the responsibility for our actions to the next generation. J. Grant C. Hopcraft, Markus Borner, Daniel T. Haydon University of Glasgow, UK, and Frankfurt Zoological Society, Germany. grant.hopcraft@glasgow.ac.uk

\section{Concern over US nuclear stewardship}

Your discussions of the failure to achieve ignition at the US National Ignition Facility (NIF; Nature 491, 159 and Nature 491, 170; 2012) raise an associated concern about the US Stockpile Stewardship Program that we believe deserves the attention of everyone concerned with the effectiveness of the US nuclear deterrent.

Experimental data from the NIF reveal that lasers can compress hydrogen fuel in fusion capsules, but ignition conditions have not been obtained.

Deficiencies in the simulations used to design ignition capsules meant that predictions for when fusion would be achieved were wrong. Worryingly, these deficiencies were not brought to light until experimental data from the NIF made their existence undeniable.

Our concern is that something similar could occur in the Stockpile Stewardship Program, which relies heavily on simulations to assess nuclearweapons performance. As with ignition, an overly optimistic assessment could result from over-confidence in simulations.

The analogy ends there, because the only experimental data that could definitively expose deficiencies in the nuclear-weapons simulations would have to be obtained from nuclear tests, which are prohibited under a moratorium. The potential consequences would be very serious.

David Sharp, Merri

Wood-Schultz Los Alamos,
New Mexico, USA. woodschultz@gmail.com

\section{Mauritius threatens its own biodiversity}

The unique biodiversity of Mauritius faces a growing threat from an unlikely source: its own government. Last week's meeting of the Intergovernmental Platform on Biodiversity and Ecosystem Services in Bonn, Germany (see go.nature.com/ dkyucn), should jolt Mauritius back into honouring its position as the first signatory to the Convention on Biological Diversity.

The Mauritian government is leasing important offshore islet nature reserves for activities that conflict with conservation objectives. This has introduced alien predators and caused the illegal destruction of protected species and habitat, without tangible consequences for those responsible. As a result, two populations of threatened endemic reptiles have already gone extinct from one of the reserves (see go.nature. com/4th4kt).

Under pressure from fruit producers, the government is 